\title{
O CASO MARYLIN MONROE: EVIDÊNCIAS DA FORCLUSÃO DO SUJEITO E DE SEU ATO
}

Jéferson Machado Pinto e Márcia Rosa

Jéferson Machado Pinto

Psicanalista,

professor do

Programa de

pós-graduação

em Psicologia da

UFMG.

Márcia Rosa

Psicanalista,

professora do

Programa de

pós-graduação

em Psicologia da

UFMG. Membro

da Escola Brasileira

de Psicanálise/

Associação Mundial de Psicanálise.

RESUMO: A objetivação da transferência sustenta uma posição epistemológica característica do discurso da ciência e implica a forclusão do real do sujeito e de sua verdade, excluindo a possibilidade do ato analítico. Para mostrá-lo, o trabalho utiliza dados biográficos e relatos das últimas sessões da análise de Marylin Monroe. Destaca que o masoquismo, vertente real do enlaçamento amoroso da atriz com o Outro, foi elidido em favor da interpretação simbólica do inconsciente e da transferência tomada como simples repetição das relações de objeto, com trágicas consequências para o sujeito.

Palavras-chave: Ato analítico, real, masoquismo, objetivação da transferência.

ABSTRACT: Marylin Monroe's case: evidences of the subject's Verwerfung and of its act. The transfer objectification is based on an epistemological position characteristic of the science discourse and implies the Verwerfung of the subject's real and of its truth, excluding the possibility of the analytical act. To discuss it, this paper uses biographical data and reports of Marylin Monroe's last analytical sessions emphasizing that masochism, the real part of the actress' love engagements with the Other, was ignored in favor of the symbolic interpretation of the unconscious and of the transfer taken as a mere repetition of the object relationships, with tragic consequences on the subject.

Keywords: Analytical act, real, masochism, transfer objectification. 
"O inesperado é uma das formas mais delicadas de prazer e a danação da busca a forma mais refinada de infelicidade."

(Michel Schneider)

$\mathrm{N}$ o Seminário XV, O ato psicanalítico, Lacan (1967-1968/s.d) tenta formalizar o percurso de uma análise e a passagem de analisante a analista a partir da lógica da fantasia, trabalhada em seu seminário anterior. Dentre as várias questões e perspectivas importantes que o Seminário XV nos traz, destacamos aqui, a partir do caso Marylin Monroe, o impasse do sujeito e a consequente persistência do sintoma, se o analista não incide com seu ato.

Com frequência, como pode ter ocorrido no caso da jovem atriz, a não incidência do ato analítico se dá por um erro de perspectiva epistemológico e ontológico. Tal erro se caracterizaria, em nosso julgamento, pela falta de compreensão do que é o ser, tal como a psicanálise o demonstra, e pela adoção de uma atitude característica do discurso científico, qual seja, a de objetivação da relação transferencial no caso estudado. Assim, a trajetória analítica de Marylin, tal como relatada por Michel Schneider (2006), servirá de recurso metodológico para tentarmos esclarecer o modo pelo qual a redução da psicanálise ao discurso da ciência e a consequente forclusão do sujeito naquilo que ele tem de mais íntimo ou próprio - no caso em questão, o seu modo específico de gozo — interferiram na direção tomada pelos analistas. Ao ser usado na expressão “forclusão do sujeito pela ciência” de modo generalizado, o termo 'forclusão', do qual Lacan se serviu inicialmente para designar a falha estrutural de operatividade da intervenção paterna nos casos de psicose, comporta uma ironia à pretensão da ciência de tratar a subjetividade com os mesmos parâmetros com os quais são tratados os objetos das ciências naturais ou exatas.

\section{UM POUCO DA HISTÓRIA DE MARYLIN}

Marylin é, ela mesma, um sintoma que persiste. Ao que tudo indica, foi a pessoa mais biografada da história. Recentemente, a psicanalista francesa MarieMagdeleine Lessana (2006) contribuiu para aumentar esse número e, também, Michel Schneider (2006), dublê de psicanalista e escritor, reconstruiu os últimos anos de análise da atriz. Ele criou uma ficção magnífica, a partir de anotações da própria Marylin, relatos, entrevistas, conferências e anotações clínicas de seus analistas, referentes às suas últimas sessões de análise.

Marylin conseguiu, a duras penas, transformar-se em atriz: "Estou tentando me tornar uma artista e ser sincera, mas às vezes sinto que estou no limiar da loucura. Estou apenas tentando expor a parte mais verdadeira do meu ser e é muito 
difícil. Tenho sempre esse sentimento secreto de que na realidade sou uma farsa, um engano” (DUNCAN, 2006, p.160, grifo nosso).

Ou: "algumas pessoas foram cruéis. Se eu digo que quero crescer como atriz, olham para o meu corpo. Se eu digo que quero melhorar, aprender minha arte, riem. De algum modo não esperam que eu leve a sério o meu trabalho" (idem).

Mesmo com o peso desse olhar do Outro, ela cresceu com grandes diretores e mostrou méritos artísticos. Criou um lugar de ícone d’A Mulher; sentia-se viva diante do olhar do Outro e sabia se colocar como portadora da feminilidade. No entanto, sabia que tudo não passava de uma imagem sem lastro: "sou um fracasso como mulher. Os meus homens esperam tanto de mim devido à imagem de sex symbol que têm de mim e que eu criei de mim mesma. Os homens esperam tanto e eu não sou capaz de corresponder a isso” (idem).

Além de estrela e ícone d’A Mulher, Marylin foi uma personagem importante no mundo psicanalítico de sua época. Ela fez sessões de análise com Ruth Brunswick e com Marianne Kris, que, por sua vez, fazia supervisão deste atendimento com Anna Freud. Marylin chegou inclusive a ir a Londres fazer algumas sessões com a filha de Freud. Na época de sua morte, aos 36 anos, fazia análise com Ralph Greenson, que também se encontrava com Anna Freud para discutir o caso. Concedeu seus direitos de imagem para o Centro Anna Freud de Londres - algo em torno de 2,5 milhões de reais/ano - porque essa instituição pretendia desenvolver a psicanálise com crianças, época da vida que Marylin destacava como o período crítico de instalação de seu sofrimento.

Registrada como Norma Jeane Mortensen (1926), abandonada pela mãe que trabalhava nos estúdios da Fox e de pai ignorado, Marylin é dada para adoção tão logo nasce. Educada com severidade até os 7 anos, a menina é devolvida à mãe biológica depois que entra em prostração devido à perda de um cãozinho, sacrificado por um vizinho. Esse fato não é sem importância para a construção de uma posição masoquista. Não é simples coincidência que sua personagem, em Os desajustados (The misfits), seu último filme, viva uma situação semelhante. O dramaturgo e então marido, Arthur Miller, escreveu o roteiro, quebrando uma promessa feita a Marylin de que jamais redigiria algo que tocasse de perto seus conflitos pessoais. Mas a personagem do filme foi criada "para realçar os dons de Marylin e fazer eco da sua natureza privada e angústias mais profundas” (DUNCAN, 2006, p.167). Nesta história, uma jovem é disputada por vários caubóis, com quem entra em desacordo, porque o trabalho deles era o de sacrificar cavalos. O filme alia sexualidade e sacrifício, fazendo uma combinação mortífera para a jovem atriz. Tais elementos estão presentes no imaginário da menina, fazendo supor uma identificação com o animalzinho sacrificado durante a conturbada infância. 
A convivência com a mãe biológica pouco durou; a mãe enlouquece, não sem antes dizer-lhe que o retrato do amigo na parede era, de fato, de seu pai. Entre idas e vindas, a criança, e depois a adolescente, passou por diversas famílias substitutivas.

A reconstituição de um sonho que a atriz tivera aos 7 anos também parece confirmar aqueles indícios de determinação de sua posição subjetiva: "nos meus sonhos eu entrava na igreja usando uma saia rodada, sem nada por baixo. Os fiéis estavam deitados de costas, eu passava por cima deles e eles olhavam sob minha saia. Sentia-me menos sozinha quando sonhava que as pessoas me olhavam" (LESSANA, 2005/2006, p.17).

Em My story, ela diz: "o meu impulso para aparecer nua e o fato de sonhar com isso não tinham qualquer sentimento de culpa ou de pecado. Sonhar com as pessoas a olharem para mim fazia-me sentir menos sozinha" (DUNCAN, 2006, p.31). A construção daquele sonho, bem como a declaração acima, indicam o percurso escolhido por ela para se fazer existir. Ser vista tornou-se igual a ser acolhida e a ter existência. E, como afirma Lacan, "não é fácil definir o que é um olhar. Esta chega a ser uma questão que pode muito bem sustentar e devastar uma existência” (1968-1969/2008, p.245), conforme bem atesta o caso da jovem atriz.

A menina que sonhava exibir-se levantando a saia se transforma na atriz que produz uma das cenas antológicas do cinema hollywoodiano: a do filme O pecado mora ao lado, em que ela segura o vestido ao passar sobre a saída de ar do metrô.

Na verdade, ela se cria como A Mulher diante das câmeras, fazendo-se existir como metáfora do atrativo sexual a partir do desejo do Outro. Ela se entregava em retribuição pelo desejo causado e dizia ao analista que não importava se a chamassem de frígida, homossexual ou prostituta. Dizia, também, fazer análise para buscar o que chamava de verdadeiro ser, além de qualquer atributo, mas julgava que poderia deitar-se com aquele que dizia amá-la, pois era o que poderia fazer por quem lhe conferia existência. Tal encarnação da erotomania decerto lhe trouxe consequências devastadoras, exemplificando o que Lacan chamou de “concessões ilimitadas que uma mulher faz para um homem: de seu corpo, de sua alma, de seus bens” (1973/2003, p.538).

Aqui é interessante abordar a junção/disjunção entre a posição feminina e a posição masoquista. As concessões ilimitadas da mulher ao Outro designam essa procura de si no Outro, e a mascarada serve a esse propósito, pois a mulher se submete às condições do amor do Outro para que a fantasia masoquista do homem situe a sua verdade. Já o sujeito estruturalmente masoquista, cuja posição subjetiva se constitui e se sustenta em um desmentido da castração, não visa o Outro por intermédio do amor, mas sim o ponto de angústia no Outro, o ponto que se situa no além da mascarada. 
Se nos reportarmos aos três modos de manifestação do masoquismo (erógeno, moral e feminino), diríamos de início que a posição subjetiva de Marylin evoca o que o autor do texto "O problema econômico do masoquismo" (1924) denominou 'masoquismo feminino', definindo-o como um desejo de ser maltratado. Esse desejo se superpõe ao infantil e faz com que o "masoquista deseja[e] ser tratado como uma criança pequena e desamparada, mas, particularmente, como uma criança travessa" (FREUD, 1924/1976, p.202).

Nesse caso, o adjetivo feminino não se restringiria à posição feminina; Freud mesmo o observa ao exemplificá-lo com relatos de casos de homens, na sua maioria. Nessa forma de gozo, que dá sustentação a uma posição fantasmática, o feminino é associado à passividade e o masoquismo surge como uma tentativa de fazer existir A Mulher, isto é, uma mulher sem limites, sem barreiras. À diferença do sujeito estruturalmente perverso, que faz existir A Mulher desmentindo a castração, nessa leitura fantasmática 'ser mulher é sofrer'; portanto, quanto maior for o sofrimento, mais próximo o sujeito estaria de uma espécie de essência intangível que seria o feminino. Em vista disso, pode-se evocar a proposta de Lacan, quando fala que não há como escrever A Mulher sem barrar o A. Para o psicanalista francês, assim como a verdade, que não pode ser senão semidita, também a mulher só poderia ser tomada no registro da incompletude e da indecidibilidade. Desse modo, ela estaria inscrita na lógica fálica, mas não-toda, uma parte dela escaparia em ser registrada nessa espécie de contabilidade discreta e descontínua que é a contabilidade fálica. Por mais que tentasse, o sujeito não conseguiria zerar o cálculo. Lacan o formula nos termos: "a mulher não é toda, há sempre alguma coisa nela que escapa ao discurso” (1972-1973/1982, p.46).

"As pessoas tinham o hábito de olhar para mim como se eu fosse uma espécie de espelho em vez de uma pessoa. Eles não me viam, eles viam seus próprios pensamentos perversos, depois disfarçavam chamando a mim de perversa" (DUNCAN, 2006, p.119). Assim, Marylin via claramente a perversão do Outro e a própria dialética do olhar, e, de algum modo, sabia jogar com a opacidade de um objeto que faz a "mancha" e nos faz olhar. O corpo que ela exibe induz à fantasia da presença daquilo que não se pode ver, evocando no Outro algo do inesperado, como no exibicionismo padrão. Ela sabia criar a cumplicidade com o Outro, ou seja, tinha conhecimento do que se produzia no Outro quando se dava a ver.

Assim, era mestra na arte de ser vista, como disse Stern (2007), o fotógrafo de sua última sessão de fotos, com a mobilidade evocadora de gestos executados de modo preciso, a fim de incluir o espectador na cena da exibição. Jogava, assim, com uma perfeição intrínseca de quem dependia disso para existir, com a busca desse objeto enquanto ausência. Mas, "a mancha também pode simbolizar o olhar que determina o sujeito como receptáculo da angústia causada por ser 
observado" (QUINET, 1997, p.161), e, se havia essa angústia, Marylin a tratava com Demerol, barbitúricos e muito champanhe. Ao mesmo tempo, e além de tudo isso, acatava aquela perversão do Outro, colocando-se devastadamente como objeto da fantasia masculina.

Podemos evocar brevemente a disjunção efetuada por Lacan (1964/1988) em O Seminário, livro 11, os quatro com conceitos fundamentais, entre o olhar e a visão. Ali, ele fala sobre a satisfação da contemplação. Ela só ocorre se a dimensão do olhar não se mostra. Assim, uma mulher se satisfaz em se saber olhada na condição de que não se mostre isso a ela. É porque Isso olha, mas também Isso mostra. Mostra o quê? O que está para além da aparência, além da mascarada, além ou aquém da imagem na sua função de ideal. Na dialética da aparência, no além da aparência, não há coisa em si, há olhar. Assim, o dar a ver pode ser entendido como uma possibilidade de encarnação da falta, fazendo surgir o olhar no lugar da queda/subtração da visão. Para tal, é necessário que o trabalho de análise possibilite uma travessia da identificação à posição de objeto no fantasma masculino, objeto gozado e maltratado, e franqueie uma posição na qual o objeto opera como semblante, ou seja, em que algo disso se apresentaria mais no registro da cena, do parecer. Advertido da falta a ser, e tendo aceitado perder essa libra de carne que se sacrifica com a própria entrada no registro da linguagem, o sujeito não estaria compelido a buscar fazer-se um ser de modo frenético, ou seja, a chegar à coisa em si, à custa de um gozo masoquista que lhe é, no mais das vezes, devastador.

Aqui cabe enfatizar que, ao denominar uma das manifestações do masoquismo como "feminino", Freud não se referia a uma suposta natureza masoquista da mulher. Shermann (2003), Soler (2005), Laurent (1999) e Ribeiro (2008), por exemplo, já problematizaram as más leituras da tese freudiana que confundiam masoquismo feminino com natureza masoquista da mulher, mas Greenson parece ter acertado quando apontou para a posição masoquista de Marylin (LESSANA, 2006, p.157). O seu caso seria exemplar, pois evidencia algo além da posição feminina, de colocar-se como objeto da fantasia masculina, com a qual uma mulher consente ou não; com Marylin, podemos aventar a hipótese de que o masoquismo opera aí como a vertente real do laço com o Outro. Ou seja, ao consentir em jogar com o "fazer-se maltratar" ela se inscrevia no jogo e no gozo fálico, configurando aí uma posição denominável como "masoquismo feminino", em termos freudianos.

No entanto, havia algo a mais, algo que apontava para mais além do falo. Parece-nos que a posição masoquista de Marylin se aproximaria, em última instância, daquilo que Freud denominou "masoquismo erógeno". Depois de ter estabelecido, em 1920, a pulsão de morte como primária, ele pôde postular a hipótese de um masoquismo erógeno, decorrente de uma parte da pulsão 
de morte não defletida por Eros, uma parte que permaneceria interna e libidinalmente fixada. Após afirmar que esse primeiro masoquismo - prazer no sofrimento - " "permanece incompreensível a menos que se decida efetuar certas suposições sobre assuntos que são extremamente obscuros” (FREUD, 1924/1976, p.201-202), o nosso autor afirma que esse masoquismo permanece no fundo das outras formas de masoquismo.

No caso de Marylin, tal como veremos a seguir, esse gozo, esse "prazer no sofrimento", será colocado a serviço de uma busca incessante de fazer existir A Mulher e de fazer existir a relação sexual, expressão pela qual Lacan observa que entre sujeito e objeto só pode existir um encontro marcado pela linguagem, e que a linguagem introduz no campo amoroso e sexual uma série de equívocos e mal-entendidos incontornáveis, uma vez que estruturais. Desconhecê-los ou pretender desfazê-los leva a uma vã ou devastadora tentativa de fazer existir a relação sexual.

\section{A CONDUÇÃO DO CASO MARYLIN}

Ralph Greenson diz que sua "esquizofrênica preferida” foi uma órfã, uma criança abandonada que provocava as pessoas de modo masoquista, para que a maltratassem e dela se aproveitassem. $\mathrm{O}$ ato de perversidade a que Marylin foi submetida por Frank Sinatra e seu amigo, o mafioso Sam Giancana, em castigo por sua entrega aos irmãos Kennedy, bem o demonstra. Schneider comenta algo que ela teria dito ao seu analista, sem precisar se relatava um fato acontecido ou se fabulava na sessão: um dia, colocou uma peruca preta e saiu a pé pelas ruas de Los Angeles, querendo andar só e não ser reconhecida. No entanto, ao passar por um posto de serviços, um rapaz que abastecia o carro a reconheceu. Ele ofereceu-lhe ajuda e uma carona para levá-la onde bem quisesse, mas ela mesma propôs a casa dele. No momento da relação sexual com um desconhecido, ela sugeriu a penetração anal e realizou o intercurso sob prantos, com dor e humilhação.

Apesar do possível acerto de Greenson sobre a localização do masoquismo da atriz, Marylin não poderia ser lida e nem se reconhecia em nenhuma das insígnias da moral sexual vigente nos anos 1950, o que dificultava o seu tratamento nos simples parâmetros da "psicologia do ego"; falta ao psicanalista americano uma leitura mais nuançada das modalidades do masoquismo estabelecidas por Freud, modalidades retomadas, com sutileza por Lacan, quando constrói a sua teoria dos gozos distinguindo o gozo fálico e, no seu mais-além, a existência de um gozo suplementar.

A atriz não se importava com clichês e fazia análise para encontrar quem era a mulher sob o nome Marylin. Quanto à Norma Jeane, essa não chegou a existir, 
pois nunca ninguém lhe declarou amor nem elogios à beleza, “coisas que toda garota necessita” (DUNCAN, 2006, p.87). Ela queria se verificar sem o poder da imagem, embora não sentisse nem o ser nem o existir fora da presença de uma câmera. O que Marylin exibia com seus sucessivos acting outs e fantasias era a busca do "verdadeiro ser", mas encontrava apenas o desespero da negativização constante das insígnias fálicas, especialmente do poder de sua imagem. Ser humilhado, ser destituído e castrado de seu poder são algumas das características apontadas por Freud em seu artigo sobre o masoquismo (1924/1976, p. 202-203). Ela se encontrava em condição propícia para o início de uma análise, mas, ao tentar adaptá-la à realidade e lhe oferecer um ambiente reparador, os analistas sustentaram sua disponibilidade ao Outro e à devastação. Não perceberam, assim, que o masoquismo poderia ser a vertente real do enlaçamento amoroso possível para Marylin.

Lacan, em seu seminário Les non-dupes errent, lição do dia18/12/1973, prossegue seu esforço de formalização e começa a esboçar um uso mais sistemático da topologia. Ali, ele supõe que os registros RSI teriam igual consistência e seriam amarrados como o nó de borromeu. Não há ainda o quarto elemento fazendo o enodamento dos três registros, apenas uma sequência de três anéis em que a falta do anel central desataria a amarração. Sua análise, naquele momento, já era promissora. Lacan cria a hipótese de que se o simbólico estivesse no centro do alinhamento dos três anéis, haveria uma predominância do amor cristão. O desejo estaria deslocado e o corpo vinculado apenas à morte. Ele utiliza um jogo de palavras e fala de um estado de a-morte, ou amorte.

No caso da amarração pela colocação do imaginário no lugar central da sequência de três, encontraríamos a situação típica do amor cortês. O real ficaria escandido, e o simbólico, apto a ser utilizado para o endeusamento da mulher, por exemplo. A inexistência da relação sexual persistiria, mas o corpo não estaria a serviço da posição mortífera. E, o que nos interessa no caso de Marylin, naquelas situações em que a amarração fosse sustentada pelo real, encontraríamos o masoquismo. ${ }^{1}$ De fato, em Marylin, o masoquismo parece ter sido a forma escolhida de enlaçamento concreto com o Outro. Por que sua capacidade de se exibir ou mesmo o uso do nome Marylin não funcionaram para sustentar sua existência? Estas poderiam ter sido soluções duradouras caso não ocorresse o incidente que lhe trouxe a morte?

\footnotetext{
${ }^{1}$ Embora pareça-nos que a retificação efetuada por Lacan a partir da ideia de sinthoma, isto é, de um quarto elemento a sustentar o enodamento de RSI, poderia nos ajudar a esclarecer o porquê do fracasso das soluções adotadas por ela, temos, quanto a isso, mais perguntas do que respostas. O interesse no desenvolvimento dessa hipótese justifica a redação de um trabalho à parte.
} 
A transferência à psicanálise, ou mesmo a Greenson, poderia sustentar uma posição subjetiva diferente ao efetuar um deslocamento da adesão ao amort (a-morte) para a construção do amûr (amuro) que poderia fazer alguma barreira ao gozo? As associações livres, gravadas em fita e enviadas a Greenson para que ele pudesse fazer as “interpretações do material”, poderiam produzir um efeito de cartas de amor (de transferência) ou apenas reforçariam o enlaçamento apoiado no simbólico ou no imaginário? Cuidar de crianças abandonadas e passar a ser a mãe que as adota por meio das doações ao Centro Anna Freud teria uma função de suplência efetiva? Ou, o analista como sinthoma possibilitaria à Marylin um modo alternativo de se enlaçar ao Outro, de criar saídas que pareciam impossíveis? O fato, porém, é que o masoquismo caracterizava a repetição, e continuou sendo seu modo predominante de relação sem nenhuma possibilidade de subjetivação. Consequentemente, esse foi o modo de Marylin sustentar a consistência do Outro.

\section{O ERRO DE PERSPECTIVA}

Mas, então, de que sujeito se trata quando falamos de Marylin? Qual seria o verdadeiro ser? Lacan, no seminário sobre o ato analítico, aponta que uma análise tem o poder de efetuar uma transformação no ser, ao possibilitar uma passagem de um falso ser — o diário de todos nós, dizia ele — para um que se move pela causa do desejo. O seminário tem, assim, pretensões de questionar a ontologia e também o lugar do saber na constituição do sujeito. Categorias que parecem bem assentadas no discurso filosófico, por exemplo, são postas à prova pelo dispositivo analítico.

A fim de esclarecer seus propósitos, Lacan recorre à matemática e à lógica (grupo de Klein) e, a partir delas, desenvolve uma rica elaboração baseada na negação e na disjunção (ou “eu não sou” ou “eu não penso”). Ele assim procede pelo simples fato de haver uma divisão entre sujeito da enunciação e sujeito do enunciado evidenciando "uma função negativa do pensar", penso onde não sou e não penso onde sou (DUNKER, 2008). A seguir, Lacan afirma que a análise parte da operação alienação ("não penso, sou") e institui a operação verdade (“penso, não sou”), a partir da operação transferência. É a transferência que faz vacilar o falso ser ao instituir o inconsciente.

A argumentação de Lacan esclarece que o ato é um operador-chave, por meio do qual o sujeito pode advir em sua irredutibilidade aos estigmas que lhe são oferecidos. Pode mesmo alcançar uma destituição subjetiva e instituir uma operação com a persistência de gozo e de linguagem, com os quais pode se identificar depois de uma análise. Mas, para tanto, é necessária uma mudança radical da posição do sujeito em relação ao saber: uma queda na suposição de 
saber e na constituição do lugar do Outro. Enquanto há transferência e suposição de saber, o ato está colocado apenas no lado do analista, pois esse não opera com o saber. A psicanálise está fora do idealismo, ao se assumir castrada e reconhecer que não há saber sobre o real do sujeito. Esse surge exatamente nos impasses do saber, e o ato funda uma nova experiência, a partir da própria ignorância de seus pressupostos (LACAN, Sem. XV, 22/11/1967, p.23). Seu compromisso é com a verdade, e o saber resta exterior, advém ou não a posteriori.

A transferência pode se tornar, dada a intrínseca relação do ato com o real, uma forma de defesa do analista diante da contingência (idem, p.30), de modo a impedir o paciente de agir, mas conduzindo-o ao acting out. A história de Marylin está carregada de exemplos que mostram o viés determinista e a objetivação da transferência adotados pelos analistas na condução desse caso clínico. As ideias de que a transferência é uma simples repetição de relações objetais e de que seria possível uma reparação dos danos sofridos na infância pareciam dominar a direção da cura. Há uma evidente forclusão do real do sujeito, aquele evidenciado pela pulsão de morte, em favor da identificação do real às produções de sentido inconscientes. Greenson chegou a levá-la para sua casa, tentando darlhe o lar que nunca teve (embora tenha vivido com pelo menos uma dezena de famílias substitutas), porque acreditava no pai como regulador do gozo. Sua filha comportava-se como irmã da atriz, e sua mulher esforçava-se para ser uma step-mother presente e acolhedora.

A família de Greenson foi apenas a última de uma longa série. Quando Monroe resolve comprar uma casa e morar só, Greenson contrata uma enfermeira e administradora dos remédios prescritos e da nova moradia, figura com quem Marylin não tinha a menor empatia e a quem descrevia como autoritária e distante. Ele foi ainda contratado pela Fox para garantir sua presença nas filmagens, administrando pílulas e recomendações de efeitos sugestivos, alimentando ainda mais os aspectos mortíferos da busca do sentido. Ao mesmo tempo, interferia nos roteiros, de modo a evitar que a atriz dissesse algumas falas, tamanha a fragilidade que atribuía a ela. Mas Marylin era incapaz de refutar a excessiva preocupação de Greenson, sentia-se incapaz de retribuir o carinho da família e se comportar como uma "boa filha". Imaginava que fazer parte da família de Greenson era um bonito sonho, mas que dependeria, segundo ela, do sucesso da análise.

Mas, como Lacan enfatiza, "em todo ato sintomático há uma abertura, um traço de luz” (Sem. XV, 22/11/1967, p.37), que, no caso de Marylin, parecia cegar a todos. A análise de Lacan a respeito das condições que sustentam a existência da própria psicanálise "permite desmontar um olhar que nos captura, ao não nos permitir apreender a estrutura mesma da cena que observamos" (LO BIANCO \& SÁ, 2006). Trata-se — pois estamos no terreno da análise do sujeito — de romper com uma estrutura da visão e "recolher o que se escreve para além do 
sensível”, como afirmam Lo Bianco e Sá (2006). A própria ideia de inconsciente subverte esta postura epistemológica porque revela que o "sujeito está sempre em posição negativa diante de sua objetivação" (DUNKER, 2008). Ou seja, o sujeito está impedido de se fazer coincidir consigo. O caso clínico, pelo menos da maneira como foi descrito por Schneider, é um retrato da psicanálise exercida na época e das práticas que eliminam a necessidade de pensar a pulsão de morte identificando o real da psicanálise ao real da ciência. Entendemos como pode ter sido difícil para os analistas a condução de um caso perpassado pela mídia e pelos holofotes de Hollywood: "Eu sabia que pertencia ao público e ao mundo, não por ser talentosa ou até mesmo bonita, mas por nunca ter pertencido a nada nem a ninguém" (DUNCAN, 2006, p.173). Mas, a condução da análise foi cega quanto ao real do sujeito e privilegiou o que era positivamente observado.

O Outro envolvido na análise de Marylin Monroe era certamente de difícil destituição, consistente, mas não personificado, poderoso, mas diluído nos diversos segmentos da estrutura capitalista, presente de maneira marcante em sua vertente perversa. O contraponto apresentado por seus analistas foi o da construção de um Outro reparador, apesar da insistência de Marylin em revelar aos seus analistas sua crença no inconsciente. Mas, parece que seu próprio apego à interpretação do sentido, relatando sonhos, gravando fitas e interpretando seus colegas de set de filmagem de modo selvagem, acabaram por seduzir a série de analistas consultados ao colocá-los em uma posição de mestria. Todos se equivocaram quanto à concepção de ser que a psicanálise introduziu no campo epistêmico sustentando a objetivação da transferência e a forclusão do sujeito.

Dez anos após a morte da atriz, Greenson diz, em uma conferência em Berkeley, após uma pergunta sobre o mistério que ainda cerca tal fato: "Nós a matamos". Com esta fala, responsabiliza-se pelo ocorrido, mas junta-se ao público e às estratégias capitalistas que pareciam gozar com o sacrifício daquele objeto que suportava a máscara d’A Mulher e seu lugar na fantasia masculina.

A psicanálise baseada no empirismo das relações objetais e no "pressuposto ideal de que o caráter normal compreende a realização da primazia genital” desconhece "que o ato analítico responde à deficiência que experimenta a verdade por sua proximidade do campo sexual” (LACAN, Sem. XV, 22/11/1967, p.38). A psicologia do Ego imagina as disposições pulsionais a serviço do Eu e idealiza a sublimação e o triunfo da satisfação objetal sobre o sintoma. O gozo fica submetido à reasonableness, ao razoável, como traduziu Lacan. Como Marylin colocava-se feito $A$ representante do Outro sexo, na tentativa de suportar o peso do Outro e se tornar indiferente ao fracasso da sublimação, acabou por adotar uma posição insustentável e evidenciou a negação da deficiência na apreensão da verdade: "o sujeito é inapto, inadequado a uma conformação ao mundo, na medida em que tem de se colocar como sujeito sexuado" (idem, 29/11/1967, p.56). O resultado 
foi desastroso, pois a busca de uma espécie de totalização mítica que faria dela um sujeito sem furos a manteve assujeitada à devastação.

Apesar das demandas, da disponibilidade e da aposta de Marylin em uma análise, o analista não alterou as coordenadas simbólicas presentes na situação. Caberia aí um ato para interromper um "estilo clássico que persiste e se desdobra". $\mathrm{O}$ ato analítico, como um ponto de basta, mostraria a verdade ligada ao real e ocorreria justo porque há algo no ser que não pode ser conhecido e nem dito. Para que se pense, é necessário que o Outro forneça o significante, e, se ele o fornece, o sujeito perde o ser, por entrar estruturalmente na alienação. Embora fantasmaticamente se movimentasse no sentido do ser, Marylin demandava análise a partir do esbarrão em uma evidente falta-a-ser, e os analistas incluíram a perda estrutural no pacote dos problemas a serem corrigidos.

Como afirma Lacan, "o analisante tem a função poética de inventar uma ficção que não se sobreponha ao ser, e o analista interpreta esse fazer porque se apoia na transferência" (Sem. XV, 06/12/1967, p.65); entretanto, o analista deve escutar que tal ficção se apoia em uma falta-a-ser e que, por isso mesmo, há ali uma demanda de análise.

Torna-se interessante aqui o comentário de Michel Schneider quando afirma não ter encontrado outro modo possível de tratar a dimensão de real em jogo no encontro entre Marylin e Greenson, entre o cinema e a psicanálise, entre as imagens e as palavras, a não ser pelo gênero ficção. Ou seja, não se tratava de biografar e de relatar fatos, buscando a verdade de modo policialesco. Portanto, ao romancear as últimas sessões de análise de Marylin, o escritor acredita ter abordado “o conflito irredutível que existe, em cada um de nós, entre as imagens e as palavras” (SCHNEIDER, 2006, s/p). Para ele, a verdade surge na confrontação permanente entre as imagens, as representações que nós temos, e as palavras que podemos colocar-lhes abaixo, como legendas. Isso ocorre no cinema, no qual se está todo o tempo confrontado ao fato de saber se o que o ator diz é verdadeiro ou não, e seria verdadeiro no tratamento analítico também. Ele localiza aí o sintoma que conduziu Marylin à psicanálise: diante das câmeras, ela experimentava, com muita angústia, uma discordância entre a imagem que transmitia e as palavras que a faziam dizer. No entanto, na análise com Greenson, o tratamento desse sintoma fez com que, aos poucos, ela se tornasse uma mulher de palavras, e ele, um homem de imagens, o que o deixou assujeitado "à lógica terrível das máquinas de fazer dinheiro que são os estúdios hollywoodianos” (ibidem). E, digamos en passant, à sua analisante também.

Schneider observa que, entre 1945 e 1965, Hollywood produziu um número incrível de filmes que representavam explicitamente o tratamento psicanalítico, seja sob a forma do psi que resolve todos os problemas, seja sob a forma maléfica do psi cindido (que encontraremos mais tarde em personagens como Hannibal 
Lecter, o serial killer). Na época de Marylin, todos os produtores, realizadores e atores estavam sobre os divãs! O cinema hollywoodiano dos anos 1940 era feito por personalidades extraordinariamente brilhantes, inteligentes, com frequência judeus imigrados da Europa Central, oriundos dos mesmos países que os psicanalistas (Áustria, Hungria, Alemanha...), nota ele, e "a fascinação era recíproca: esses dois mundos fizeram de Hollywood uma capital cultural" (SCHNEIDER, 2006, s/p).

Em vista disso, não é sem interesse a resenha de Marylin, últimas sessões, feita pelo escritor Phillippe Sollers no Le Nouvel Observateur de 14 de setembro de 2006. Depois de intitular o seu comentário "Marylin ou a suicidada do espetáculo”, alusão evidente a Antonin Artaud e ao seu livro Van Gogh, o suicidado da sociedade, Sollers observa que a Hollywood daquele tempo era em realidade um grande hospital psiquiátrico fechado sobre milhões de dólares. Não sem ironia e questionando a direção do tratamento feito por Greenson, Sollers sugere que Freud, que acreditava ter levado a peste à América, teria ficado bastante surpreso ao ver que a sua chocante descoberta tinha sido atingida, ela própria, por uma peste virulenta. Posto isso, ele indaga: “O que teria feito Lacan com Marylin?”. E diz:

\footnotetext{
"Nada, ou não grande coisa. Ele ter-lhe-ia demonstrado por seus silêncios, e suas tiradas espirituosas inspiradas, que ele era absolutamente alérgico à indústria cinematográfica, a Hollywood, a toda essa salada de dinheiro e de pseudossexo. Ele ter-lhe-ia cobrado preços loucos para vir vê-lo por dez minutos. Ao invés de materná-la e de lhe fazer almoçar em família, ele ter-se-ia mostrado indiferente aos seus filmes e aos seus amantes. Kennedy? Sinatra? Arthur Miller? Os diretores? A Máfia? Bravos garotos, nenhum interesse! Freud, ele próprio? Sem dúvida, mais ainda. Anna Freud? Sigamos. Em suma, clínico experiente no campo da psicose, muito pouco humano, invencível à sedução, com uma paciente incomparável, portadora do mais exorbitante narcisismo de todos os tempos, ele teria impulsionado a paranoia até o limite. Que cena! Marylin, descoberta, teria se cansado e poderia tê-lo morto porque ele não lhe teria sequer solicitado uma foto. Eis o drama da América, e talvez do mundo: a psicanálise não existe mais quando o cinema tomou o lugar do real." (SOLLERS, 2006, s/p)
}

Com isso, poderíamos supor que Lacan teria buscado incidir sobre a vertente real do enlaçamento amoroso da atriz com o Outro. Se Ralph Greenson operava produzindo injeções de sentido e por atos com que tentava retificar o estado de satisfação pulsional no nível da realidade, tal como mostram as intervenções nas relações objetais, Lacan ter-se-ia feito indiferente ao estrelismo de Marylin de modo a poder intervir no campo de satisfação pulsional que o mantinha operante. A esse respeito, e referindo-se aos comentários mencionados acima, 
Eric Laurent observa que "Philippe Sollers sonhava com um encontro impossível entre Lacan e Marylin, um Lacan ainda mais star que Marylin, e completamente indiferente a ela, o que talvez lhe tivesse dado a chance de ter um destino menos trágico" (LAURENT, 2009, p.37-38).

\section{CONCLUSÃO}

A condução do caso pelos analistas da época mostra que a busca da adaptação à realidade desconsidera a base do princípio do prazer porque há um gozo na insatisfação. Há algo de verdade nesse gozo da insatisfação primordial e no masoquismo, e essas seriam as referências a serem buscadas. Por isso, percebemos com Lacan, que falta uma compreensão do ato ali aonde falta compreensão do que é o ser. Os analistas de Marylin persistiram na vertente empirista da epistemologia, na qual o ser é identificado a um objeto da percepção, e esqueceramse do fundamental. Para que uma análise prossiga, o analista teria de chegar a um ponto de redução do sintoma que lhe permitiria questionar em que a experiência de análise afeta o ser e evoca a verdade do gozo. Caso contrário, o sintoma persistirá.

Marylin exibiu como uma estrela a face mortífera do gozo, o que nos permite recolocar mais uma vez o alerta lacaniano: "quem se engaja no ato deve estar em posição definida, pois apesar de todo ato falho ser bem-sucedido em fazer brilhar a verdade, não implica que a falha seja signo de sucesso do ato" (LACAN, Sem. XV, 6/12/1967, p.63).

\section{REFERÊNCIASS}

DUNKER, C.I.L. (2008) “Descartes e o método psicanalítico”, in Estudos Lacanianos, v.1, n.1. Belo Horizonte: Scriptum, p.169-186.

DUNCAN, P. (2006) Monroe - movie icons. Hong Kong: Taschen.

FREUD, S. (1976/1976) Edição standard brasileira das obras psicológicas completas de Sigmund Freud. Rio de Janeiro: Imago.

(1924) “O problema econômico do masoquismo”. v.XIX, p.195-212.

LACAN, J. (1964/1988) O Seminário, livro 11. Os quatro conceitos fundamentais da psicanálise. Rio de Janeiro: Jorge Zahar. crifa, s/d. (1967-1968) O Seminário, livro XV. O ato psicanalítico. Edição apó(1968-1969/2008). O Seminário, livro 16. De um Outro ao outro. Rio de Janeiro: Jorge Zahar. 
(1972-1973/1982) O Seminário, livro 20. Mais, ainda. Rio de Janeiro: Jorge Zahar.

(1973/1974) Les non-dupes errent. Inédito.

LAURENT, E. (1999) Posiciones femininas del ser: del masoquismo femenino al empuje a la mujer. Buenos Aires: Editorial Três Haches.

. (2009) O real do sinthoma (ou a inocência do sinthoma), Opção Lacaniana. Revista Brasileira Internacional. n.54. São Paulo.

LESSANA, M-M (2006) Marylin, retrato de uma estrela. Rio de Janeiro: Jorge Zahar.

LO BIANCO, A.C. \& SÁ, R. (2006) “A objetividade do experimento: a elisão do sujeito e de seu ato”, in BASTOS, A. (Org.), Psicanalisar hoje. Rio de Janeiro: Contra Capa Ed. e Programa de Pós-graduação em Teoria Psicanalítica da UFRJ.

QUINET, A. (1997). "O olhar como um objeto”, in FELDSTEIN, R.; FINK, B.; JAANUS, M. (Orgs.). Para ler 0 seminário 11 de Lacan. Rio de Janeiro: Jorge Zahar Editor.

RIBEIRO, C.N. (2008). "Reduzir-se a nada. Articulações entre masoquismo, feminino e máscara”. Dissertação de Mestrado aprovada pelo Programa de Pós-graduação em Psicologia da UFMG.

SCHNEIDER, M. (2006). Marylin dernières séances. Paris: Bernard Grasset.

Michel Schneider parle de son livre. Extraído de http://www. pileface.com/Sollers. Acesso em dezembro de 2008.

SHERMAN, E.Z. (2003). O gozo en-cena: sobre o masoquismo e a mulher. São Paulo: Escuta.

SOLER, C. (2003). Ce que Lacan disait des femmes. Paris: Éditions du Champ lacanien.

SOLLERS, Ph. (2006) Marylin ou la suicidée du spectacle, Le Nouvel Observateur, n.2.184. Semaine du Jeudi 14 septembre. Extraído de http:// hebdo.nouvelobs.com. Acesso em dezembro de 2008.

STERN, B. (2007). Marylin, o mito. Rio de Janeiro: Sextante.

\author{
Jéferson Machado Pinto \\ jmachadopinto@gmail.com \\ Márcia Rosa \\ marcia.rosa@globo.com
}

